\title{
Arte de guerrilha no Brasil ditatorial: \\ O caso das produções de Cildo Meireles e Hélio Oiticica pela via filosófica de Giorgio Agamben.
}

Walace Rodrigues

\section{Resumo}

Este artigo tenta analisar algumas obras de Cildo Meireles e Hélio Oiticica durante o período de resistência cultural no Brasil ditatorial (1964-1985). Para tanto, tomamos em conta o período de ditadura militar brasileira como uma época de estado de exceção, tão bem conceituado pelo filósofo italiano de Giorgio Agamben, do qual faremos uso neste artigo. Pretende-se aqui uma melhor compreensão da arte de guerrilha de Cildo Meireles e Hélio Oiticica durante o Brasil ditatorial.

Palavras-chave

Cildo Meireles, Hélio Oiticica, ditadura militar, Giorgio Agamben.

\begin{abstract}
This article aims to analyze some artworks by Cildo Meireles and Hélio Oiticica during the cultural resistance period in dictatorial Brazil (1964-1985). To do so we will take in account the period of Brazilian military dictatorship as a time of state of emergency, so well conceptualized by Italian philosopher Giorgio Agamben, which we will use in this article. We intend to get to a better understanding about the guerrilla art by Cildo Meireles and Hélio Oiticica during dictatorial Brazil.
\end{abstract}

\section{Keywords}

Cildo Meireles, Hélio Oiticica, military dictatorship, Giorgio Agamben. 


\section{Introdução}

Na América Latina, durante as décadas de 1960, 1970 e 1980, vários países passaram por regimes ditatoriais militares, onde as forças militares controlavam completamente a máquina do Estado tentando eliminar influências socialistas que pudessem exercer poder sobre a sociedade.

No Brasil, a ditadura militar foi instaurada em 1964 e oficialmente terminada em 1985. O período mais autoritário da ditadura brasileira aconteceu depois da criação do Ato Institucional número 5 (Al-5), em 13 de dezembro de 1968, que suspendia todos os direitos civis dos cidadãos. A partir deste ato a vida cultural brasileira mudaria de rumo com a forte influência da censura pública sobre todos os campos das artes. Uso aqui uma passagem de Randal Johnson (2004) onde ele clarifica este ponto, dando especial atenção à literatura:

O golpe de estado militar de 1964, que iniciou vinte e um anos de regra ditatorial, obviamente teve um grande impacto na literatura e cultura brasileiras. Numerosos trabalhos de ficção tem explorado o impacto e as ramificações do autoritarismo e do movimento de resistência que se ergueu contra ele. (JOHNSON, 2004, p. 131) Tradução nossa.

Muito se fala sobre as artes e suas manifestações contra a ditadura militar, principalmente na área da criação musical, cinematográfica e plástica. E dois dos influentes artistas desta época que participaram desta resistência artística contra a ditadura foram Cildo Meireles e Hélio Oiticica. Com suas atitudes de contestação do sistema, eles nos deram bons exemplos para analisar as noções de vazio e impossibilidade geradas pela ditadura militar, além de reverterem, em seus trabalhos, concepções prezadas pelos militares. Também, este trabalho pretende, utilizar o conceito de estado de exceção de Giorgio Agamben para caracterizar a ditadura militar no Brasil, exemplificando a contestação deste estado militar com uma obra no campo das artes plásticas. 


\section{Desenvolvimento}

A ditadura militar no Brasil ocorre num período confuso dentro da história política brasileira. O então presidente Jânio Quadros renuncia em 1961, deixando o cargo ao seu vice-presidente João Goulart, que tinha novas ideias de reforma sociais e econômicas. De acordo com Da Costa e Sergl (2007), o ..."governo de Goulart é marcado pelo agravamento da crise econômica e pela intensa vida política, bem como pelos conflitos sociais e políticos no país. Diante disso, alegando combater a subversão e assegurar a ordem democrática, os militares tomam o poder na noite de 1 de abril de 1964" (COSTA; SERGL, 2007, p. 35-36).

Os efeitos do golpe militar na vida dos cidadãos não se fazem sentir bruscamente com a entrada dos militares no poder em 1964. Somente com a instauração do Ato Institucional número 5 (Al-5) de 13 de dezembro de 1968 é que um órgão de censura foi criado dentro do governo e os direitos civis dos cidadãos foram suspensos, plenos poderes foram concedidos ao presidente militar (tais como: fechar o Legislativo por tempo ilimitado, cassar mandatos, suspender direitos políticos, suspender a garantia do habeas corpus e efetuar prisões sem mandado judicial). A partir deste momento, os militares mostram seu lado mais autoritário e truculento. Durante este período tudo é proibido e os jovens estudantes politizados começam a mostrar a grande insatisfação com o regime militar. A partir do Al-5 a classe artística começa intensificar os "ataques culturais" contra a ditadura. As obras de teatro, cinema, musica, artes plásticas, entre outras, são divididas entre as que protestam contra o regime e as que apoiam o regime.

Podemos, então, relacionar o momento histórico de suspensão dos direitos civis e políticos dos cidadãos com o estado de exceção caracterizado por Agamben. Giorgio Agamben, filósofo italiano, tradutor de Walter Benjamin para o idioma italiano, dá aulas na Facoltà Di Design e Arti della IUAV, em Veneza. Sua obra e pensamento centram-se nas relações entre filosofia, literatura, direito, poesia e política. Sua obra Estado de Exceção explora a relação filosófica com o direito e a política dentro do que os juristas buscam entender como sendo o estado de exceção. 
O estado de exceção é um mecanismo jurídico utilizado por regimes totalitários onde, legalmente, se suspendem os direitos legais dos cidadãos para a criação de um Estado político onde um "soberano"1 define as normas e regulamentos. Agamben (2005) diz que:

\begin{abstract}
...totalitarismo moderno pode ser definido como o estabelecimento, pelo meios no estado de exceção, de uma gerra civil legal que permite a eliminação física, não só dos adversários políticos mas de uma inteira categoria de cidadãos que por alguma razão não podem ser integrados ao sistema político. (AGAMBEN, 2005, p. 2) Tradução nossa.
\end{abstract}

Da mesma maneira podemos caracterizar a ditadura militar brasileira depois de Al-5, pois os direitos civis dos cidadãos foram suspensos e a perseguição, censura e tortura contra os inimigos do regime ocorreram cotidianamente. A classe artística politizada protestava em suas obras, utilizando um discurso de contestação, enquanto outros artistas instauravam um discurso de alienação social.

Assim, o estado de exceção traz uma nova ordem jurídica que deve ser observada intimamente relacionada a um estado de necessidade. Agamben (2005) nos informa que:

Como uma figura de necessidade, o estado de exceção mesmo aparecendo (ao lado da revolução e do estabelecimento de fato de um sistema constitucional) com um "ilegal" mas como uma medida perfeitamente "jurídica e constitucional" que acarreta na produção de novas normas (ou de uma nova ordem jurídica). (AGAMBEN, 2005, pág. 28) Tradução nossa.

\footnotetext{
1 "A contiguidade essencial entre estado de exceção e soberania foi estabelecida por Carl Schmitt em seu livro Politische Theologie (1922). Embora sua famosa definição do soberano como "aquele que decide sobre o estado de exceção" tenha sido amplamente comentada e discutida, ainda hoje, contudo, falta uma teoria do estado de exceção no direito público, e tanto juristas quanto especialistas em direito público parecem considerar o problema muito mais como uma quæstio facti que como um genuíno problema jurídico" (AGAMBEN, Revista Trópico).
} 
Então, podemos, de certa forma, dizer que a aprovação inicial de parte da sociedade brasileira ao golpe militar de 1964 mostrava uma necessidade de mudança política no Brasil de princípios dos anos 60 .

Também, é importante lembrar que o estado de exceção é um mecanismo jurídico que funciona como uma justificativa legal para um estado politicamente "ilegal", já que o estado de exceção traz em si a suspensão da lei (as leis existem, porém não estão em força, ou seja, não podem ser aplicadas). E ainda, de acordo com Agamben, “...o estado de exceção separa a norma de sua aplicação possível. Ele introduz uma zona de anomia dentro da lei para criar uma regulação efetiva [normazione] do real possível" (idem, p. 36, tradução nossa). Desta maneira, baseados nesta zona de anomia, os militares puderam eliminar as pessoas que eram ferozmente contra seu governo, entre elas intelectuais, jornalistas, estudantes, artistas, entre tantas outras.

No estado de exceção, o uso da violência é incluído na lei através de sua própria exclusão, já que encontra-se numa zona de anomia (idem, p. 54). Esse é um dos fundamentos básicos do estado de exceção: a inclusão excludente. Com esse mecanismo de incluir excluindo, os militares mataram vários cidadãos e cometeram atrocidades. Apesar de terem uma maneira de justificar sua violência, eles não aceitavam uma possível violência causada pelo povo insatisfeito.

Há uma íntima relação entre estado de exceção e guerra civil. No espaço da guerra civil a população dá uma resposta, geralmente violenta, aos conflitos vividos por um país ou região. Assim, o estado de exceção pode se relacionar à uma "guerra civil", já que este é a resposta imediata do poder estatal aos conflitos internos mais extremos. A criação voluntária de um estado de emergência permanente (mesmo que não declarado em sentido mais técnico) tornou-se uma das práticas essenciais dos Estados contemporâneos, inclusive dos que são chamados democráticos. Essa discussão sobre o estado de emergência é ponto fundamental na visão teórica de Agamben, já que “...necessidade não tem lei”, o que pode ser interpretado de duas maneiras: "necessidade não reconhece nenhuma lei" e "necessidade cria sua própria lei" (idem, 24, tradução nossa), causando um vazio legal e sendo a base da discussão jurídica sobre estado de exceção, mesmo hoje em dia, em países ditos democráticos. 
Agamben nos diz que "...ditadura, no entanto, o qual abrange o estado de emergência, é essencialmente um "estado de exceção", e na medida em que ele se apresenta como uma "suspensão da lei" (idem, p. 32, tradução nossa). Assim como os militares brasileiros instauraram um novo governo como um estado de siege ou emergência ${ }^{1}$, instaurando suas próprias normas, podemos verificar a íntima ligação entre a ditadura militar e o estado de exceção utilizado por Agamben.

Os militares brasileiros que estavam no poder foram responsáveis por mortes, exílios, prisões, torturas e desaparições que não seriam permitidas se não estivessem dentro de um estado de exceção, que, de alguma maneira, Ihes dava poderes bastante para cometer essas atrocidades. A Delegacia de Ordem Política e Social (Dops) foi o órgão responsável pela repressão de vários artistas e intelectuais dentro deste estado de exceção caracterizado aqui como ditadura militar, que afetou profundamente a vida artística brasileira.

Cildo Meireles (1948) é um artista carioca de grande renome nacional e internacional. Durante a ditadura militar ele fez vários trabalhos questionando os sistemas da arte e da política. O catálogo da mostra Documenta IX nos dá uma breve introdução sobre sua obra:

Na década de 1960 ele resistiu clima político repressivo de seu país com o seu trabalho crítico, e esta intenção pode ainda ser sentida em muitos de seus trabalhos atuais. Sua posição artística esta em algum lugar entre Arte Conceitual e Performance.(BECKER, 1992, p. 165) Tradução nossa.

Cildo é um destes artistas sem uma classificação definida dentro dos "ismos" da história da arte, ele circula entre áreas, o que somente valoriza suas criações e reforça esse ânimo de revolta criativa que dá vida a seus trabalhos ${ }^{1}$.

1 "O estado de emergência não é um "estado de lei", mas um espaço sem lei" (AGAMBEN, 2005, p. 51, tradução nossa).

Veja uma ilustração de "Inserções em Circuitos Ideológicos: Projeto Cédulas", obra de 1975, no website http://www.bbc.co.uk/collective/gallery/2/static.shtml?collection=brazil\&image=2 
Portanto, neste artigo nossa análise se volta para a obra "Inserções em Circuitos Ideológicos. Projeto Cédulas", de 1975. Trata-se de uma performance com um caráter bastante político e contestador dos limites de poder sobre a interferência na vida dos cidadãos. Ele carimba notas de 1 Cruzeiro (notas válidas da época) com a pergunta "Quem Matou Herzog?" e devolve estas notas à circulação normal, utilizando-as em suas compras diárias. Essa obra segue a mesma linha de um famoso projeto seu de 1970 intitulado "Inserções em Circuitos Ideológicos. Projeto Coca-Cola" que foi exibida na mostra Information no Museu de Arte Moderna de Nova Iorque (MOMA-NY). Meireles usou silkscreen para colocar em garrafas de Coca-Cola várias mensagens, entre elas a "Yankees go home" (algo como "Americanos voltem pra casa"), e colocou as garrafas de volta em circulação. Ai ele utiliza-se dos sistemas de distribuição de bebidas de uma marca tão cara ao capitalismo para fazer circular informação sem nenhum tipo de controle centralizado.

A obra "Inserções em Circuitos Ideológicos: Projeto Cédulas" se refere ao jornalista Vlado (usava o nome Vladimir) Herzog (1937-1975), que foi torturado e morto pelos militares do DOI-CODI (Destacamento de Operações de Informações Centro de Operações de Defesa Interna, um dos órgãos repressivos do regime militar brasileiro) em São Paulo. O caso da morte do jornalista inflamou as críticas aos regimes militares latino-americanos e deu força a protestos de todas as formas. Uma destas formas de protesto contra os abusos do regime militar se deu pela via artística, como nos informa Valerie Fraser (2004) no artigo Art and architecture in Latin America: "No Brasil, sob a ditadura militar do final dos anos 60, os neoconcretistas experimentaram com formas interativas de arte de todas as maneiras mais ou menos subversivas" (FRASER apud KING, 2004, p. 216, tradução nossa).

Cildo sofre grande influência da geração neoconcreta e sempre utilizase da questão do espectador como ator, uma das principais características das obras dos artistas neoconcretos. No momento em que ele dá estas cédulas carimbadas ao comerciante, colocando-as novamente em circulação, começa o processo de colocar as pessoas como potenciais participantes de suas obras, fazendo com que essas pessoas leiam e reflitam sobre o que está escrito nas notas e o que isto representa para elas. Ele cria uma corrente de contestação, de questionamentos. 
Analisando mais detalhadamente a obra "Inserções em Circuitos Ideológicos. Projeto Cédulas" podemos verificar que Cildo joga com a noção do sistema de circulação monetário, um sistema do qual nós não nos damos conta no dia-a-dia. Essa noção se cristaliza na forma da cédula (papel-moeda) circulante. 0 artista recolhe a cédula e trabalha sobre ela, ou seja, tira-a de circulação para carimbá-la, intervindo nesse processo temporal do sistema de circulação, marcando definitivamente esta cédula com a pergunta. A cédula, desta forma, faz com que nos demos conta da materialidade do sistema monetário, que questionemos as políticas monetárias do governo, enquanto a pergunta nos faz refletir sobre a legitimidade e a crueldade do sistema militar. Uso aqui uma passagem onde Cildo nos fala sobre a importância do espectador em sua obra:

Nem sempre a função é buscar a beleza. Talvez o percurso esteja muito mais ligado à questão da verdade do que da beleza. O que eu acho interessante no objeto de arte é quando ele sequestra o espectador, naquele lugar e naquele momento. Mesmo que seja por milionésimos de segundo, está você e o objeto, você sai daquele lugar, naquele momento, e vive uma experiência única, por mais breve que seja... Não é um êxtase, mas é alguma coisa que altera profundamente a tua relação normal com aquele espaço, aquela rua, aquela cidade, aquele país, entendeu? É quando o objeto faz o sujeito esquecer-se de si mesmo. Para mim, isso está muito próximo do que é a beleza em arte. (MEIRELES apud HERZOG, 2006, p. 74).

Esse estranhamento do objeto, que pode ser um objeto de uso diário, é exatamente a ideia dada por Marcel Duchamp (1887-1968) sobre seus readymades. Porém, o readymade de Duchamp se diferenciam dos de Cildo Meireles, como, por exemplo, na instalação "Projeto Cédulas". Ali Cildo reintegra o objeto (cédula) ao sistema de trocas vigente. Ciro utiliza um objeto (o suporte para sua obra) já feito (industrializado, readymade), intervém sobre ele e o recoloca em uso corrente, ativando a reflexão sobre o objeto e seus sistemas de uso e valor.

Por outro lado, Duchamp utiliza um objeto já feito (também suporte para sua obra), intervém sobre ele e o retira de seu uso normal "transformando-o" 
em objeto de reflexão artístico-filosófica. Duchamp dá nova função ao objeto industrializado deslocando-o de seu uso habitual, dando a este objeto uma função "artística". Cildo recoloca o objeto industrializado, após intervenção, no mesmo sistema de onde ele saiu. De alguma forma Duchamp paralisa o objeto, enquanto Cildo o faz entrar em movimento.

Ainda, Meireles expande a concepção sobre sua obra (seus happenings) a partir do momento em que não restringe o objeto a um museu ou galeria de arte, mas o recontextualiza sem que este perca o sentido de uso, porém estigmatizado-o, ressignificando-o com intensidade, recolocando-o na vida real e em seu uso corrente, mas agora com um nome que não deve ser esquecido: Herzog. Essa ressignificação cultural e simbólica do objeto, no caso de "Inserções em Circuitos Ideológicos: Projeto Cédulas", pode ser vista, também, como uma estratégia política, onde, analogicamente, o retirado do sistema (o jornalista morto) volta de uma outra forma a fazer parte do mesmo sistema do qual foi retirado, numa forma mais simbólica, através de seu nome sendo visto e repetido inúmeras vezes.

Víctor Zamudio-Taylor (2006) citando Moacir dos Anjos reforça esta visão mais política: "Se Marcel Duchamp intervém ao nível da Arte (lógica dos fenômenos), o que se faz atualmente é o contrário, tende-se a estar mais próximos da Cultura do que da Arte, e isso é necessariamente uma interferência política" (ZAMUDIO-TAYLOR, 2006, p. 93). O que Cildo faz é reintroduzir na cultura de massa (pois a cédula atingirá o grande público capitalista) os nomes que os militares querem esquecidos. Ele intervém no sistema cultural e monetário via suas cédulas, mas sem gritar, sem passeatas, somente via uma forma de protesto silencioso, porém não menos significativo e forte que uma passeata, por exemplo.

O valor emocional da obra "Inserções em Circuitos Ideológicos: Projeto Cédulas" é bastante forte, bastante pungente, pois lida com sentimentos de dor, angústia, tristeza, insatisfação, revolta, etc. Cildo Meireles nos informa sobre o valor emocional da sua obra:

Eu acho que as artes plásticas não deveriam perder essa possibilidade que têm de se relacionar emocionalmente com o espectador. Isso é um ganho. Por exemplo, acho que um dos problemas da arte conceitual é que ela foi se tornando muito verbal, muito fria. (MEIRELES apud ZAMUDIO-TAYLOR, 2006, p. 72). 
E ainda:

Me interessa fazer trabalhos que emanem algum tipo de sedução emocional também. Na verdade, me interessa muito que os trabalhos tenham esse tipo de característica (idem, p. 72).

Toda essa carga emocional dos trabalhos de Cildo Meireles também podem ser na performance "Inserções em Circuitos Ideológicos: Projeto Cédulas", já que a cédula ressignificada nos leva a pensar nas vítimas da ditadura militar e repudiar o regime de governo ditatorial instalado no Brasil.

Não é somente a questão sentimental importante nas obras de Cildo Meireles, mas a questão do concreto com o simbólico é, também, fundamental na sua obra, onde ele problematiza o material, o simbólico e a relação entre eles. $\mathrm{Na}$ referida obra há um jogo com a adição do valor físico da cédula a um valor simbólico, o que redefine o significado do trabalho e nos faz questionar sobre o valor do dinheiro, do sistema monetário, da vida das pessoas, dos direitos adquiridos e do papel da própria arte enquanto mecanismo de contestação. Sendo o conceito de valor em arte muito difícil de definir, uso aqui uma passagem de Koerner e Rausing (2003), onde eles nos informam sobre a dificuldade de conceituar a questão do valor em arte e a complexidade de matérias envolvidas:

A disciplina de história da arte de hoje em dia faz, no entanto, uso de conceitos mais gerais sobre o valor imputado à arte. As quatro influencias dominantes aqui, recebidas dos campos da economia, antropologia, linguística e psicologia, respectivamente, são Karl Marx, Marcel Mauss, Ferdinand de Saussure e Sigmund Freud. Teorias críticas atuais do objeto de arte como valioso são usualmente uma colcha de retalho ou bricolages de todas as quatro, mediadas por um grupo de revisionistas e antigos bricoleurs, até eles conseguirem uma completamente desconcertante complexidade. (KOENER; RAUSING, 2003, p. 428) Tradução nossa.

Marx ligando o valor do objeto artístico à sua maneira particular de produção, Mauss à lógica do presente, Saussure ao seu valor simbólico e Freud à teoria da sublimação são, como nos diz a passagem, as quatro referências ligadas à conceituação de valor dos objetos artísitcos. 
Outra questão importante para analisar na obra de Cildo Meireles é a questão da ruptura, a ruptura dos sistemas, a ruptura das ideias pré-concebidas sobre arte. É através da ruptura que a arte se faz Arte. A ruptura traz o questionamento das formas conhecidas de pensar Arte. Uma das intenções das obra "Inserções em Circuitos Ideológicos: Projeto Cédulas" é exatamente, dentro das coisas banais da vida diária, como usar uma cédula para pagar algo, questionar, através da pergunta carimbada, os sistemas que nos envolvem e nos fazem viver sem pensar. Meireles reforça essa questionamento sobre a arte e a vida: "Você não sabe 90\% das coisas que nós [artistas] fazemos, 99,9\% são absolutamente redundantes, são variações de coisas já feitas, não tem ali nada de ruptura, não tem um dado realmente novo, entende?" (MEIRELES apud ZAMUDIO-TAYLOR, 2006, p. 75). Na obra "Inserções em Circuitos Ideológicos: Projeto Cédulas" o dado novo é a intervenção, o carimbo, a marca, um novo "signo" na cédula que nos faz começar a refletir.

Com o estado de exceção implantado no Brasil pela ditadura militar, os mecanismos que possibilitavam que as pessoas pensassem foram bruscamente interrompidos com a criação da censura pública. Nada podia ser questionado, nada podia ser feito sem que se fosse vigiado, os artistas não podiam criar livremente, as pessoas não podiam expressar seus pensamentos publicamente por medo de serem torturadas, como no caso do jornalista Vladimir Herzog. A criação artística de Meireles foi sutil em incorporar os sistemas usados pelos militares contra eles mesmos. Meireles está dessacralizando e democratizando a arte através da circulação das cédulas usadas por todos e transformadas em objetos artísticos de contestação e reflexão através da mensagem explícita e anônima, forçando os limites dos sistemas de percepção e compreensão dos espectadores-participantes.

O ponto da anonimidade da autoria da obra é, também, bastante relevante. Sabemos que a história da arte trabalha com a noção de artista enquanto ser único e especial, ou seja, aquele que assina a obra, como Marcel Duchamp assina o urinol (mesmo que seja com um nome falso!). Colocando um objeto anônimo em circulação é retirada a máscara de criador genial do artista. Também, isso fez com que o artista pudesse proteger-se das possíveis represálias dos 
militares. A ideia da materialidade trabalhada em favor do pensar venceu a força bruta militar. O artista se utiliza da arma da re-inclusão do nome do jornalista Herzog na vida das pessoas, na sociedade que o conhecia.

Um outro artista a qual nos referimos aqui é Hélio Oiticica (1937-1980): carioca, participante ativo do movimento neoconcreto, é considerado por muitos críticos da arte o Warhol das artes brasileiras, já que sua contribuição para as artes brasileiras é inestimável em vários campos. Em 1959 funda com Lydia Clark, Franz Weissmann e Amilcar de Castro o grupo Neoconcreto, mudando de vez as feições da arte moderna brasileira.

O manifesto neoconcreto, escrito pelo poeta Ferreira Gullar (um manifesto publicado no Jornal do Brasil em 22 de Março de 1959) se opunha contra a visão mecanicista e objetivista da arte concreta e propunha uma estética mais emocional, mais afetiva, mais próxima ao homem e aos organismos vivos. Tempo, espaço, forma e cor se uniam na obra neoconcreta, transcendendo o espaço mecânico e as noções de causa e efeito. O geometrismo inicial do movimento se relacionava agora à complexidade das realidades humanas. Assim colocou Gullar (1959) no manifesto:

Não concebemos a obra de arte nem como 'máquina nem como 'objeto` , mas com um quasi-corpus, isto é, um ser cuja realidade não se esgota nas relações exteriores de seus elementos; um ser que, decomponível em partes para análise, só se dá plenamente à abordagem direta, fenomenológica. (GULLAR, 1959).

Exemplo desses quasi-corpus podem ser vistos nas obras de Oiticica, principalmente através das obras chamadas "Bólides". Oiticica utilizava o termo bólide para todos os objetos que serviam como invólucro de algo ou alguém. Neste mesmo sentido, seus famosos Parangolés, coloridas capas-mantos, feitos a partir de 1964, que eram utilizados em "ações" pelos expectadores, caracterizando um happening onde participava ativamente o expectador (ativando as potencialidades do trabalho artístico), eram, considerados por Oiticica, também, como bólides. A natureza humana de seus objetos, mesmo os mais geométricos, nos intriga, nos 
emociona e nos faz refletir sobre a função da arte. Oiticica "...deixa de enfatizar o sentido visual para pôr em jogo o conjunto dos sentidos, mais precisamente o corpo inteiro, concebido como 'plenitude"' (BRETT apud ADES, 1997, p. 264). Esse interesse pelas pessoas o leva a viver na favela da Mangueira, no subúrbio do Rio. Aí ele mantinha um segundo atelier, onde criou seus Parangolés para serem "vestidos" pelos moradores da Mangueira, reconhecendo neles a famosa "ginga carioca" e sua riqueza expressiva de movimentos.

No ano de 1965, quando Oiticica frequentava habitualmente a Mangueira, a polícia matou um marginal chamado Cara de Cavalo, pessoa com quem Oiticica tinha contato na favela. Oiticica desfilou como passista no carnaval daquele ano pela Mangueira, esta foi umas das experiências marginais do artista para poder compor a sua própria obra artística. Ele tentou dar voz ao mundo marginalizado do Morro da Mangueira através de sua presença na favela. Os jornais noticiaram a morte do marginal com uma foto que Oiticica usou para compor um estandarte, com a técnica da serigrafia sobre tecido, alterando a legenda original do jornal e re-escrevendo a seguinte frase: "SEJA MARGINAL. SEJA HERÓI". Essa obra foi exposta na Boate Sucata durante um show dos Mutantes com Gilberto Gil, o que causou o fechamento da boite e justificou a perseguição aos músicos. A obra tinha o nome de "Homenagem A Cara de Cavalo", o que era, claramente, uma afronta aos militares.

A obra de Oiticica é um ataque direto aos conceitos de boa conduta de sua época, `a falsa moralidade do governo militar e ao conservadores da época. Oiticica incorpora a revolta do favelado, de ser discriminado pela população e pelo poder público como marginal. Oiticica inverte os valores sociais da época, dando voz ao favelado, ao marginal sem voz, ele recusou-se a qualquer preconceito, a qualquer discriminação, sendo tolerante ao extremo e reconhecendo-se, também ele, como um ser marginal (à margem de tudo) e livre para agir no mundo, reafirmando sua individualidade e seus valores estéticos: o que importava era o homem, a pessoa humana.

Sua obra enfurece os militares por ser vista por eles como imoral e valorizadora do bandido, do marginal, do excluído. Em verdade, o que fez Oiticica, assim como Meireles, foi re-incluir o morto no sistema de pensamento público, 
questionando a posição do marginalizado e a injustiça social, instigando as pessoas a serem marginais, a pensarem livremente, a utilizarem seus poderes de criadores de ideias e de ações para mudarem o mundo. Oiticica também utilizou-se do mesmo conceito da inclusão excludente do estado de exceção, onde o morador da favela é um típico exemplo disto: ele está incluído na sociedade, de acordo com o poder público, porém não tem os serviços dados pelo mesmo poder público à classe média. Oiticica reintegra o marginal (a imagem sem face do marginal, irreconhecível) na sociedade, faz com que as pessoas pensem sobre o marginal de maneira positiva, de maneira criativa, produtiva, transgredindo 0 pensamento moral estabelecido da época sobre ser "pessoa em sociedade" e sobre o valor da arte. Afinal, quais eram os verdadeiros bandidos da história da época?

O uso de um estandarte, objeto caracteristicamente visto nas festas populares brasileiras, dá à obra uma ligação ainda mais humana aos festejos da vida e seus ritos de passagem. Assim a morte de Cara de Cavalo pode ser vista como um acontecimento que marca a sociedade durante o período da ditadura militar, que marca a sua importância como povo e vira herói dos marginalizados, como que chamando a atenção da população para a situação marginal dos favelados, contra o governo militar que nega direitos, e a favor de uma marginalização criativa, de uma margem questionadora e reflexiva.

\section{Conclusão}

Durante o estado de exceção vivido no Brasil da ditadura militar as ideologias eram controladas pelos chefes do regime enquanto os cidadãos sobreviviam em um estado autoritário e limitador de direitos civis. Esse estado de exceção também alimenta as poéticas criativas dos artistas da época, engajados em fazer o povo refletir. Neste sentido, a arte de Cildo Meireles e Hélio Oiticica reforçaram a luta em favor da informação e da formação de um pensar independente e livre de repressões, ativando o poder criador e gerador de novas ideias.

A censura oficial sobre todas as áreas da vida cultural brasileira, durante a ditadura, foi devastadora, porém não foi forte o bastante contra artistas com um poderio de fogo cultural avassalador. O cinema, a música e o jornalismo 
foram áreas que sofreram com a forte censura e repressão militar, daí eu ter tomado uma obra de arte relacionada à repressão contra um jornalista. Os direitos dos cidadãos eram os de concordar com o governo militar e acatar as decisões tomadas, mostrando o autoritarismo vigente que restringia os direitos civis e políticos dos cidadãos, características do estado de exceção. Daí a escolha, também, de uma obra que põe em foco a população marginal no Brasil. É em meio a esse caos político que as obras de arte de Cildo e Hélio se impõem como mecanismos de questionamento, de fazer pensar. A materialidade do objeto, a sua presença física instigando a reflexão, pode ser relacionada à palavra "matter" em inglês, que é ao mesmo tempo matéria e questão.

É importante lembrar acerca das ideologias implantadas pelo governo militar, para que saibamos discernir entre o que liberta e o que oprime, e entre o que faz pensar e o que cerceia o pensamento. A América Latina e seus cidadãos sofreram muito durante as ditaduras militares com as privações de direitos, e é nosso dever fazer com que tais regimes não tenham mais força para acontecerem no futuro. Temos que ver, também, que cada país latino-americano é diferente e não pode seguir exemplos padronizados. Canclini (1992) nos fala dessas distintas lógicas de desenvolvimento dentro da América Latina: "Hoje concebemos a América Latina como una articulação mais complexa de tradições e modernidades (diversas, desiguais), um continente heterogêneo formado por países onde, em cada um, coexistem múltiplas lógicas de desenvolvimento" (CANCLINI, 1992, p. 23, tradução nossa). Essa diversidade e desigualdade pode ser vista no dia-a-dia e, através da arte, pode ser pensada e questionada.

Os militares somente tinham como fim a preservação do estado de exceção implantado pela ditadura militar, um estado de privações intelectuais e de direitos que afetaram profundamente a vida dos latino-americanos. Porém, verificamos que a forte resistência ao estado autoritário brasileiro se deu no campo artístico. E nas obras de Cildo Meireles e Hélio Oiticica pudemos verificar a articulação do sistema contra o sistema: do sistema de percepção e compreensão da arte dentro de um sistema de repressão do pensar. A ditadura militar também deixou sua marca nas pessoas, assim como a cédula foi marcada pelo carimbo, a obra e a vida de vários artistas também ficou marcada. Os artistas que vivenciaram esse momento de autoritarismo na história brasileira foram tocados e tiveram que 
pensar uma arte engajada mas não ingênua, e que pudesse fazer questionar aos cidadãos mais antenados e acordar os que estavam sonolentos. 